\title{
Influence of gestational diabetes on the long-term control of glucose tolerance
}

\author{
G. Seghieri • F. Tesi • R. Anichini • A. De Bellis • \\ E. Barsotti • A. Mari • E. Ferrannini
}

Received: 21 March 2007 / Accepted: 9 July 2007 / Published online: 1 September 2007

(C) Springer-Verlag 2007

\begin{abstract}
Aims/hypothesis Gestational diabetes (GDM) carries a high risk of subsequent diabetes. We asked what impact prior GDM has on beta cell function and insulin action in women who maintain normal glucose tolerance (NGT) for a long time.

Methods Ninety-one women with NGT (aged $41 \pm 8$ years, mean \pm SD) were studied (by mathematical modelling of the C-peptide response to an OGTT) 7 [6] years (median [interquartile range]) after the index pregnancy, during which 52 had GDM (pGDM) and 39 had NGT (pNGT). In all women an OGTT had also been performed at $29 \pm$ 3 weeks of the index pregnancy.

Results Women with pGDM were matched with women with pNGT for age, familial diabetes, time and weight gain since index pregnancy, parity, BMI $(25.4 \pm 3.9$ vs $26.8 \pm$ $\left.6.4 \mathrm{~kg} / \mathrm{m}^{2}\right)$, and fasting $(4.64 \pm 0.56 \mathrm{vs} 4.97 \pm 0.46 \mathrm{mmol} / \mathrm{l})$ and $2 \mathrm{~h}$ plasma glucose levels $(5.91 \pm 1.14$ vs $5.91 \pm$ $1.21 \mathrm{mmol} / \mathrm{l}$ ). Nonetheless, fasting (49 [29] vs 70 [45] pmol $\left.\min ^{-1} \mathrm{~m}^{-2}, p<0.001\right)$ and total insulin secretion (32 [17] vs $\left.48[21] \mathrm{nmol} \mathrm{m}^{-2}, p<0.0001\right)$ and beta cell glucose
\end{abstract}

G. Seghieri $\cdot$ F. Tesi $\cdot$ R. Anichini $\cdot$ A. De Bellis

Division of Internal Medicine, Spedali Riuniti,

Pistoia, Italy

A. Mari

CNR Institute of Biomedical Engineering,

Padua, Italy

E. Barsotti $\cdot$ E. Ferrannini $(\triangle)$

Department of Internal Medicine and CNR Institute of Clinical

Physiology, University of Pisa School of Medicine,

Via Roma, 67,

56126 Pisa, Italy

e-mail: ferranni@ifc.cnr.it sensitivity (slope of the insulin secretion/plasma glucose concentration-response function) (95 [71] vs 115 [79] pmol $\left.\min ^{-1} \mathrm{~m}^{-2}(\mathrm{mmol} / \mathrm{l})^{-1}, p=0.025\right)$ were reduced in the $\mathrm{pGDM}$ group compared with the pNGT group, while insulin sensitivity was preserved (424 [98] vs 398 [77] $\mathrm{ml} \mathrm{min}^{-1} \mathrm{~m}^{-2}$ ). At index pregnancy, women with $\mathrm{pGDM}$ and those with pNGT had similar age and BMI. However, both insulin sensitivity (359 [93] vs 417 [92] $\mathrm{ml} \mathrm{min}^{-1} \mathrm{~m}^{-2}, p=0.0012$ ) and the insulin/glucose incremental area ratio (an empirical index of beta cell function; 98 [74] vs 138 [122] pmol/mmol, $p=0.028$ ) were reduced in women with pGDM.

Conclusions Even in women who maintain normal insulin sensitivity, impaired beta cell function is carried over into the NGT status several years after a GDM pregnancy.

Keywords Beta cell function - Gestational diabetes . Insulin resistance $\cdot$ Pregnancy

\begin{tabular}{|c|c|}
\hline \multicolumn{2}{|c|}{ Abbreviations } \\
\hline GDM & gestational diabetes mellitus \\
\hline NGT & normal glucose tolerance \\
\hline pGDM & $\begin{array}{l}\text { gestational diabetes mellitus during the index } \\
\text { pregnancy }\end{array}$ \\
\hline $\begin{array}{l}\text { pNGT } \\
\text { sd.r }\end{array}$ & $\begin{array}{l}\text { normal glucose tolerance during the index pregnancy } \\
\text { standardised regression coefficient }\end{array}$ \\
\hline
\end{tabular}

\section{Introduction}

Women with gestational diabetes (GDM) have a higher risk of developing type 2 diabetes or altered glucose metabolism during the postpregnancy period [1-5]. The cumulative incidence of type 2 diabetes increases markedly in the first 
5 years after delivery, reaching a plateau after 10 years [1]. It has been suggested that the higher risk of postpregnancy diabetes represents a partial remission of GDM [6-9]. In fact, insulin resistance and beta cell dysfunction are the main pathophysiological factors of GDM just as they are for diabetes outside of pregnancy [10].

It has been repeatedly reported (reviewed in [11]) that women with normal glucose tolerance (NGT) and prior GDM carry some trace of altered glucose homeostasis, essentially, insulin resistance [8] and/or beta cell dysfunction [12-19]. Several of these studies, however, have been carried out in obese women or shortly after GDM; moreover, not all have related the abnormalities detected after GDM to those found during GDM. In the present study, we assessed beta cell function and insulin action in women with NGT with or without prior GDM both during the index pregnancy and several years later.

\section{Methods}

Participants The study participants were drawn from a larger cohort enriched with women with familial diabetes or obesity (or other reasons to suspect altered glucose tolerance), who were screened during the third trimester. While those with diabetes or IGT were systematically tested after pregnancy (and at each subsequent pregnancy) (prospective group), those with NGT were invited to return for a repeat OGTT (matching group). The present cohort included all women ( $n=91)$ currently with NGT (pNGT; based on a standard $75 \mathrm{~g}$ OGTT) who had also been studied during the third trimester of a pregnancy (index pregnancy) at least 2 years previously. The study protocol was approved by the local ethics committee, participants gave their informed consent to participate, and the study was conducted in accordance with the principles of the Declaration of Helsinki.

Clinical studies A frequently sampled OGTT was carried out in all participants, with measurements of plasma glucose, insulin, NEFA and C-peptide concentrations. At $29 \pm 3$ weeks (mean \pm SD) of the index pregnancy, all women had received another $75 \mathrm{~g}$ OGTT, with measurement of plasma glucose and insulin (but not C-peptide) concentrations at baseline and 1,2 and $3 \mathrm{~h}$ after glucose ingestion.

Measurements Plasma glucose was measured by the glucose oxidase method (Glucose Analyzer; Beckman Instruments, Fullerton, CA, USA). Plasma NEFA were assayed spectrophotometrically (Wako, Neuss, Germany); plasma insulin and C-peptide were assayed with specific RIA kits (Linco Research, St. Louis, MO, USA).
Data analysis Insulin sensitivity was estimated from the plasma glucose and insulin levels measured during the OGTT by the oral glucose insulin sensitivity (OGIS) method [20]. From the frequently sampled OGTT at follow-up, beta cell function was resolved by mathematical modelling [21, 22]. In brief, insulin secretion rates were reconstructed by deconvolution of C-peptide concentrations and related to plasma glucose levels (in a concentration-response relationship, the average slope of which was taken as beta cell glucose sensitivity) and to the rate of change of plasma glucose levels (representing rate sensitivity). Insulin clearance was calculated as the ratio of total post-OGTT insulin secretion to the average post-OGTT plasma insulin concentration.

In order to compare beta cell function between the two OGTTs, an empirical index was obtained as the insulin/glucose incremental area ratio $\left(\Delta \mathrm{AUC}_{\mathrm{I}} / \Delta \mathrm{AUC}_{\mathrm{G}}, \mathrm{pmol} / \mathrm{mmol}\right)$ [23]. This index expresses the overall ability of the beta cell to increase its release rate in response to the total glycaemic stimulus presented. In the present data set, this index and the

a

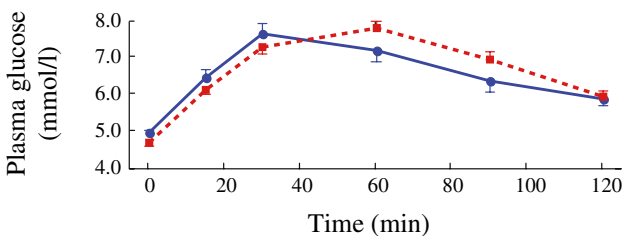

b
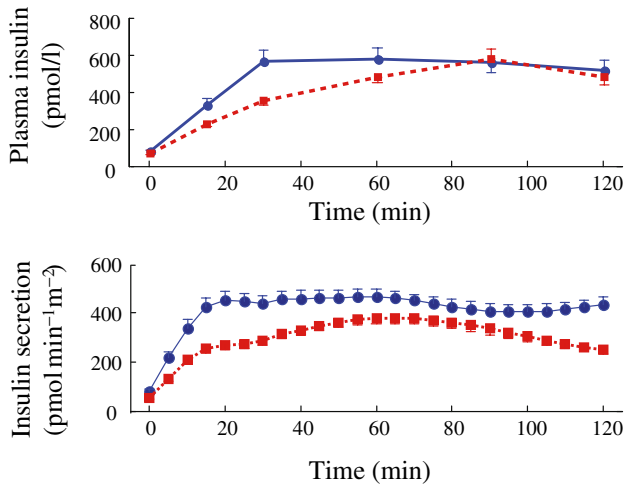

d

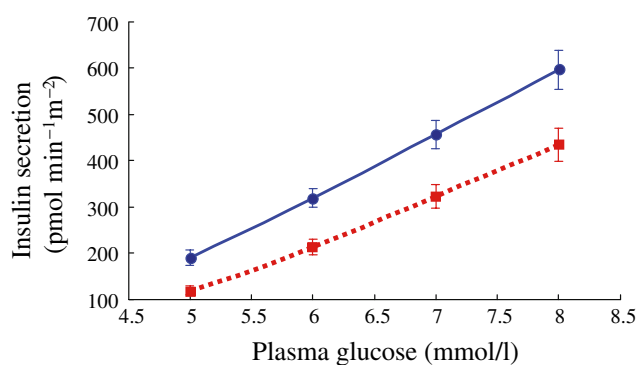

Fig. 1 Plasma glucose (a) and insulin (b) concentrations, insulin secretion rates (c) and insulin/glucose concentration-response functions (d) in women with (squares and dotted line) or without (circles and continuous line) previous GDM during the OGTT at follow-up 
model-derived specific index of beta cell function (i.e. beta cell glucose sensitivity) were directly related to one another $(\rho=0.47, p<0.0001)$.

Statistical analysis Results are given as mean $\pm \mathrm{SD}$ and median [interquartile range] for variables with a normal and non-normal distribution respectively. The AUCs were calculated by the trapezoidal rule. Group comparisons were carried out with the $\chi^{2}$, Student's $t$ and Mann-Whitney $U$ tests as appropriate. Simple associations were tested by Spearman rank correlation $(\rho)$; multiple regression analysis was carried out after log-transformation of non-normally distributed variables; results are given as standardised regression coefficients (sd.r). An alpha level of 0.5 was considered statistically significant.

\section{Results}

Women with pGDM were matched to women with pNGT for age, prevalence of familial diabetes, time from index pregnancy, parity, BMI, fasting and $2 \mathrm{~h}$ plasma glucose levels. The two groups had gained weight similarly both during and since the index pregnancy. Fasting plasma insulin and NEFA concentrations and insulin sensitivity were not significantly different between the two groups. In contrast, the plasma insulin response to glucose was markedly reduced in the pGDM group, particularly early after ingestion (Fig. 1). Insulin secretion (fasting as well as post-glucose) and both rate sensitivity and glucose sensitivity were significantly reduced in the pGDM group (Table 1). In the pGDM group, the concentration-response curve of insulin secretion was shifted downwards compared with that in the pNGT group, such that insulin release was lower at any given plasma glucose concentration (Fig. 1). The insulin/glucose incremental area ratio was also significantly reduced in the pGDM group (Table 1).

At the time of the index pregnancy, the two groups were matched for age, pregestational weight and weight gain during pregnancy. By definition, fasting and $2 \mathrm{~h}$ glucose levels were higher in the pGDM than in the pNGT group. Both insulin sensitivity and the insulin/glucose incremental

Table 1 Clinical and metabolic parameters

\begin{tabular}{|c|c|c|c|}
\hline & $\begin{array}{l}\text { pGDM } \\
(n=52)\end{array}$ & $\begin{array}{l}\text { pNGT } \\
(n=39)\end{array}$ & $p$ value $^{\mathrm{a}}$ \\
\hline \multicolumn{4}{|l|}{ Post index pregnancy } \\
\hline Age (years) & $41 \pm 5$ & $41 \pm 5$ & NS \\
\hline Familial diabetes $(\%)$ & 41 & 43 & NS \\
\hline Time from index pregnancy (years) & $7[6]$ & $8[5]$ & NS \\
\hline Parity $(n)$ & $2.0[1.0]$ & $2.0[1.5]$ & NS \\
\hline BMI $\left(\mathrm{kg} / \mathrm{m}^{2}\right)$ & $25.4 \pm 3.9$ & $26.8 \pm 6.4$ & NS \\
\hline Weight change since index pregnancy $(\mathrm{kg})$ & $4.3 \pm 6.9$ & $5.7 \pm 8.9$ & NS \\
\hline Fasting plasma glucose $(\mathrm{mmol} / \mathrm{l})$ & $4.64 \pm 0.56$ & $4.97 \pm 0.46$ & NS \\
\hline $2 \mathrm{~h}$ plasma glucose $(\mathrm{mmol} / \mathrm{l})$ & $5.91 \pm 1.14$ & $5.91 \pm 1.21$ & NS \\
\hline Fasting plasma NEFA (mmol/l) & $0.57 \pm 0.16$ & $0.57 \pm 0.18$ & NS \\
\hline Fasting plasma insulin (pmol/1) & $71[45]$ & $72[29]$ & NS \\
\hline$\Delta \mathrm{AUC}_{\mathrm{I}} / \Delta \mathrm{AUC}_{\mathrm{G}}(\mathrm{pmol} / \mathrm{mmol})$ & $143[146]$ & $296[287]$ & 0.002 \\
\hline Insulin sensitivity $\left(\mathrm{ml} \mathrm{min} \mathrm{m}^{-1} \mathrm{~m}^{-2}\right)$ & $424[98]$ & $398[77]$ & NS \\
\hline Insulin clearance $\left(1 / \mathrm{m}^{2}\right)$ & $0.75[0.53]$ & $0.81[0.35]$ & NS \\
\hline Fasting insulin secretion $\left(\mathrm{pmol} \mathrm{min}-1 \mathrm{~m}^{-2}\right)$ & $49[29]$ & $70[45]$ & $<0.001$ \\
\hline Total insulin output $\left(\mathrm{nmol} / \mathrm{m}^{2}\right)$ & $32[17]$ & $48[21]$ & $<0.0001$ \\
\hline Beta cell glucose sensitivity $\left(\mathrm{pmol} \mathrm{min}^{-1} \mathrm{~m}^{-2}[\mathrm{mmol} / \mathrm{l}]^{-1}\right.$ ) & $95[71]$ & $116[79]$ & 0.025 \\
\hline Beta cell rate sensitivity $\left(\mathrm{nmol} \mathrm{m}{ }^{-2}[\mathrm{mmol} / \mathrm{l}]^{-1}\right)$ & $0.71[0.75]$ & $1.15[1.42]$ & $<0.01$ \\
\hline \multicolumn{4}{|l|}{ At index pregnancy } \\
\hline Age (years) & $33 \pm 4$ & $33 \pm 4$ & NS \\
\hline Pre-pregnancy BMI $\left(\mathrm{kg} / \mathrm{m}^{2}\right)$ & $23.8 \pm 3.2$ & $24.6 \pm 4.3$ & NS \\
\hline Pregnancy weight gain $(\mathrm{kg})$ & $9.1 \pm 3.9$ & $9.9 \pm 3.1$ & NS \\
\hline Fasting plasma glucose $(\mathrm{mmol} / \mathrm{l})$ & $4.98 \pm 0.65$ & $4.71 \pm 0.53$ & 0.043 \\
\hline $2 \mathrm{~h}$ plasma glucose $(\mathrm{mmol} / \mathrm{l})$ & $9.52 \pm 1.07$ & $7.07 \pm 1.46$ & $<0.0001$ \\
\hline Fasting plasma insulin (pmol/1) & $60[52]$ & $54[44]$ & NS \\
\hline Insulin sensitivity $\left(\mathrm{ml} \mathrm{min} \mathrm{m}^{-1} \mathrm{~m}^{-2}\right)$ & $349[93]$ & $403[95]$ & 0.0012 \\
\hline$\Delta \mathrm{AUC}_{\mathrm{I}} / \Delta \mathrm{AUC}_{\mathrm{G}}(\mathrm{pmol} / \mathrm{mmol})$ & $98[74]$ & $138[122]$ & 0.028 \\
\hline
\end{tabular}

Data are mean $\pm \mathrm{SD}$ or median [interquartile range]

${ }^{a} \chi^{2}$, Student's $t$ or Mann-Whitney $U$ 
area ratio were significantly lower in the pGDM than in the pNGT group (Table 1).

In multivariate analysis, insulin release (as the insulin/ glucose incremental area ratio) and insulin sensitivity were independent determinants of $2 \mathrm{~h}$ plasma glucose levels both at the index pregnancy (sd.r $=-0.54$ and -0.76 , respectively; $p<0.0001$ for both, $\left.r^{2}=0.46\right)$ and follow-up (sd.r $=-0.52$ and -0.46 respectively; $p<0.0001$ for both, $r^{2}=0.43$ ), independently of age and BMI. In the pGDM group but not the pNGT group, beta cell glucose sensitivity at followup was directly associated with time since index pregnancy (sd.r=0.67, $p<0.0001)$ independently of age (sd.r $=-0.38$, $p<0.02$; total $r^{2}=0.28 ; p=0.0003$ ) (Fig. 2).

\section{Discussion}

Several years after the index pregnancy, our previously GDM but NGT women had plasma glucose profiles that were minimally different from those of a well-matched group of women with documented NGT during the index pregnancy (Fig. 1). Nevertheless, they showed multiple defects in beta cell function. Thus, their rates of glucosemediated insulin release (fasting as well as post-glucose) were reduced in absolute terms. When these insulin secretory rates were related to the concomitant plasma

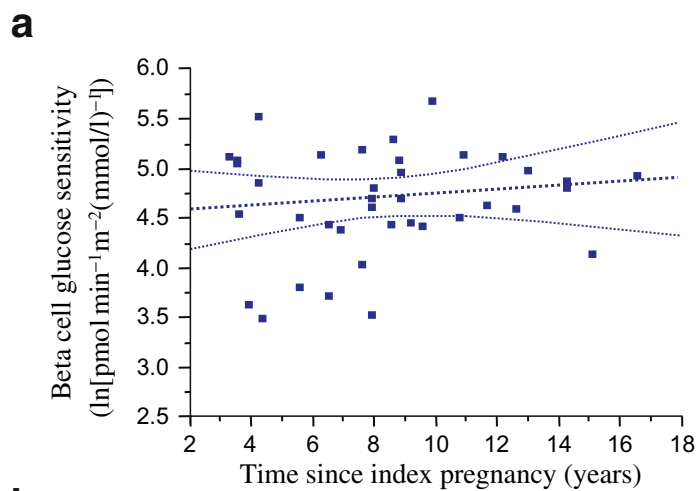

b

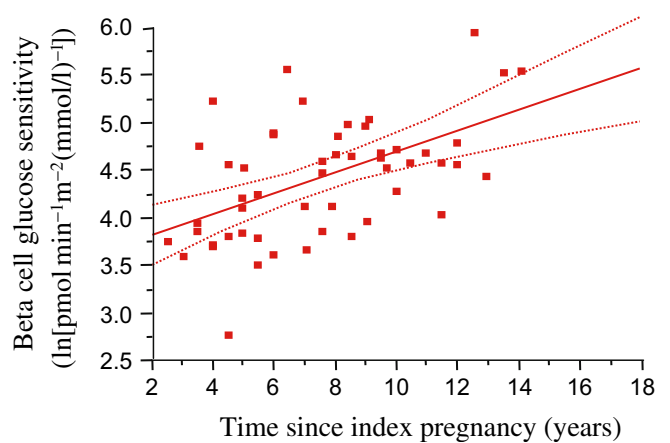

Fig. 2 Age-adjusted relationship between beta cell glucose sensitivity and time since index pregnancy in women without (a) (sd.r $=0.16$, NS) or with (b) (sd.r $=0.67, p<0.0001)$ previous GDM. Lines of best fit are shown with their $95 \%$ CIs glucose levels by modelling analysis, the ability of beta cells to sense glucose and to respond to its rate of change was clearly impaired. This impairment was reflected also by the insulin/glucose incremental area ratio, an empirical proxy for beta cell glucose sensitivity [23]. In the pGDM group, NGT was maintained by virtue of the fully preserved (in fact slightly superior) insulin sensitivity (Table 1). During the index pregnancy, on the other hand, the diabetes of women with pGDM was precipitated by the combination of impaired beta cell function (as the insulin/glucose incremental area ratio) with insulin resistance. Thus, the only abnormality that was carried over to the NGT state of later years was a defective beta cell response to glucose.

The reason why insulin sensitivity was worse in women with GDM than in 'normotolerant' women during pregnancy remains undefined, as age, BMI and weight gain during gestation, the main determinants of insulin sensitivity, were similar in the two groups. It is possible that raised glucose levels throughout the 29 weeks of pregnancy in the GDM group depressed insulin sensitivity by glucose toxicity. Whatever the cause, this insulin resistance resolved over the following several years.

The notion that some metabolic memory persists in women with prior GDM even when they present NGT has emerged from a number of previous studies [12-19]. The majority of these studies have clearly indicated that previous GDM is associated with a significant reduction in insulin sensitivity, insulin secretion or both in women who maintain NGT at follow-up [12-19]. However, uncertainty remains as a result of some bias in the design of most of these studies. Thus, the time since the index pregnancy has been very variable and, mostly, short (13 years) $[12,14,15,19]$. In other cases, mean OGTT glucose values, even if normal by diagnostic criteria, were significantly higher in normotolerant women with previous GDM than in women who had NGT during the index pregnancy $[15,19]$. Not infrequently, groups were not well matched for actual or pregestational BMI or age $[16,18$, $19]$, thereby conferring a presumably different burden of background insulin resistance [24].

Our study was free of these biases since the median time from index pregnancy to follow-up examination (7-8 years) was beyond the high-risk window for developing diabetes [1]. Furthermore, the groups were well matched both at index pregnancy and at follow-up for such confounders as age and obesity (Table 1). Finally, average glucose values during the OGTT were similar at follow-up in women with pGDM and those with pNGT (6.82 \pm 1.02 and $6.66 \pm$ $1.24 \mathrm{mmol} / 1$ respectively; Fig. 1). Under these conditions, the only detectable abnormality in the pGDM group was impaired beta cell function.

Of further interest is that beta cell glucose sensitivity at follow-up was better in pGDM women with a longer time 
interval since index pregnancy irrespective of age (Fig. 2). This finding may suggest that beta cell competence might improve with time after a GDM pregnancy. This putative phenomenon, however, would only be proven by sequential post-GDM testing over years. A more likely explanation for a cross-sectional series is selection bias, whereby NGT is increasingly more frequent in women with pGDM who are past the highest risk window of post-GDM diabetes. In general, our results do not imply that only beta cell dysfunction, and not insulin resistance, prevails in the pGDM population; they simply prove that, even in the absence of significant insulin resistance, beta cell dysfunction can still be detected in normotolerant women with pGDM. Thus, secretory impairment stands out as the dominant pathophysiological feature of gestational diabetes. Clearly, women who also maintain insulin resistance into the postgestational period are at heightened risk of incident diabetes.

Acknowledgements This work was supported in part by a grant of the Fondazione Cassa di Risparmio di Pistoia e Pescia, Pistoia, Italy.

Duality of interest The authors declare that there is no duality of interest associated with this manuscript.

\section{References}

1. Kim C, Newton KM, Knopp RH (2002) Gestational diabetes and the incidence of type 2 diabetes. Diabetes Care 25:1862-1868

2. Kjos SL, Buchanan TA, Greenspoon JS, Montoro M, Bernstein GS, Mestman JH (1990) Gestational diabetes mellitus: the prevalence of glucose intolerance and diabetes mellitus in the first two months postpartum. Am J Obstet Gynecol 163:93-98

3. Buchanan TA, Catalano PM (1995) The pathogenesis of GDM: implications for diabetes after pregnancy. Diabetes Rev 4:584-601

4. Ben-Haroush A, Yogev Y, Hod M (2004) Epidemiology of gestational diabetes mellitus and its association with type 2 diabetes. Diabet Med 21:103-113

5. Chan SP, Gelding SV, McManus RJ et al (1992) Abnormalities of intermediary metabolism following a gestational diabetic pregnancy. Clin Endocrinol (Oxf) 36:417-420

6. Catalano PM, Huston L, Amini SB, Kalhan SC (1999) Longitudinal changes in glucose metabolism during pregnancy in obese women with normal glucose tolerance and gestational diabetes. Am J Obstet Gynecol 180:903-916

7. Xiang AH, Peters RK, Trigo E et al (1999) Multiple metabolic defects during late pregnancy in women at high risk for type 2 diabetes mellitus. Diabetes 48:848-854
8. Homko C, Sivan E, Chen X, Reece EA, Boden G (2001) Insulin secretion during and after pregnancy in patients with gestational diabetes mellitus. J Clin Endocrinol Metab 86:568-573

9. Buchanan TA (2001) Pancreatic B-cell defects in gestational diabetes: implications for the pathogenesis and prevention of type 2 diabetes. J Clin Endocrinol Metab 86:989-993

10. Catalano PM, Kirwan JP, Haugel-de-Mouzon S, King J (2003) Gestational diabetes and insulin resistance: role in short- and longterm implications for mother and fetus. J Nutr 133:1674S-1683S

11. Buchanan TA, Xiang TA (2005) Gestational diabetes mellitus. J Clin Invest 115:485-491

12. Efendic S, Hanson U, Persson B, Wajngot A, Luft R (1987) Glucose tolerance, insulin release, and insulin sensitivity in normal weight women with previous gestational diabetes mellitus. Diabetes 36:413-419

13. Dornrhost A, Edwards SG, Nicholls JS et al. (1991) A defect in insulin release in women at risk of future non-insulin-dependent diabetes. Clin Sci 81:195-199

14. Ward WK, Johnston CLW, Beard JC, Benedetti TJ, Halter JB, Porte D Jr (1985) Insulin resistance and impaired insulin secretion in subjects with histories of gestational diabetes. Diabetes 34:861869

15. Kautzky-Willer A, Prager R, Waldhausl W et al (1997) Pronounced insulin resistance and inadequate beta-cell secretion characterize lean gestational diabetes during and after pregnancy. Diabetes Care 20:1717-1723

16. Kousta E, Lawrence N, Godsland IF et al (2003) Insulin resistance and b-cell dysfunction in normoglycaemic European women with a history of gestational diabetes. Clin Endocrinol 59:289-297

17. Kirvan JP, Huston-Presley L, Kalhan SC, Catalano PM (2001) Clinically useful estimates of insulin sensitivity during pregnancy. Diabetes Care 24:1602-1607

18. Ryan EA, Imes SH, Liu D et al (1995) Defects in insulin secretion and action in women with a history of gestational diabetes. Diabetes 44:506-512

19. Lencioni C, Volpe L, Miccoli R et al (2006) Early impairment of beta-cell function and insulin sensitivity characterizes normotolerant Caucasian women with previous gestational diabetes. Nutr Metab Cardiovasc Dis 16:485-493

20. Mari A, Pacini G, Murphy E, Ludvik B, Nolan JJ (2001) A model-based method for assessing insulin sensitivity from the oral glucose tolerance test. Diabetes Care 24:539-548

21. Mari A, Tura A, Gastaldelli A, Ferrannini E (2002) Assessing insulin secretion by modeling in multiple-meal tests: role of potentiation. Diabetes 51(Suppl 1):S221-S226

22. Mari A, Schmitz O, Gastaldelli A, Oestergaard T, Nyholm B, Ferrannini E (2002) Meal and oral glucose tests for the assessment of beta-cell function: modeling analysis in normal subjects. Am J Physiol Endocrinol Metab 283:E1159-E1166

23. Ferrannini E, Mari A (2004) Beta cell function and its relation to insulin action in humans: a critical appraisal. Diabetologia 47:943-956

24. Seghieri G, De Bellis A, Anichini R, Alviggi L, Franconi F, Breschi MC (2005) Does parity increase insulin resistance during pregnancy? Diabet Med 22:1574-1580 